\title{
Reactive Hyperplastic Lesions of the Gingiva: A Retrospective Study of 260 Cases
}

\author{
Sangeetha Ramu, Charlotte Rodrigues
}

\begin{abstract}
Objectives: The purpose of the study was to analyze the frequency and distribution of gingival lesions in MR Ambedkar Dental College, Bengaluru.
\end{abstract}

Materials and methods: The material included the biopsies of all localized reactive hyperplastic lesions (LRHL) of the gingiva stored in the department's database (1995-2011). The lesions were analyzed according to their location and the patient's age and gender. The findings were compared with other published studies on reactive lesions.

Results: A total of 260 reactive lesion biopsies were accessed. focal fibrous hyperplasia (FFH) was the most common (38.5\%), followed by pyogenic granuloma (PG) $(34.6 \%)$, peripheral ossifying fibroma (POF) $(17.7 \%)$ and peripheral giant cell granuloma (PGCG) (9.2\%). The mean age of the patients was 33 years, with a range varying from 9 to 80 years. The LRHL occurred more commonly in females except focal fibrous hyperplasia, which showed male predilection. PG and POF were more common in the maxilla and FFH as well as PGCG were more common in the mandible.

Conclusion: This study indicates some differences in age and gender distribution as well as in location between the different lesions. The results of this study differ from those of other studies and the data presented here can be used as a guide for further multicenter studies.

How to cite this article: Ramu S, Rodrigues C. Reactive Hyperplastic Lesions of the Gingiva: A Retrospective Study of 260 Cases. World J Dent 2012;3(2):126-130.

\section{Source of support: Nil}

Conflict of interest: None declared

\section{INTRODUCTION}

Growths of the gingival tissues are common and often result from underlying systemic disease, drug-induced stimulus, local iatrogenic factors and dental plaque. The lesions described in this study are considered reactive lesions that are nonneoplastic in nature and not implicated with drug involvement. ${ }^{1}$

The histological classification of localized reactive hyperplastic gingival lesions (except for giant cell granulomas) is somewhat confusing in the literature. ${ }^{2}$ Kfir et al have specifically classified gingival lesions into pyogenic granuloma, peripheral giant cell granuloma, fibrous hyperplasia and peripheral fibroma with calcification. $^{3}$

Nowadays, the accepted classification of localized reactive hyperplastic lesions (LRHL) of the gingiva is into four types: Focal fibrous hyperplasia $(\mathrm{FFH})$, pyogenic granuloma (PG), peripheral ossifying fibroma (POF) and peripheral giant cell granuloma (PGCG). ${ }^{4}$

The aim of the study was to review the clinicopathologic features of localized reactive hyperplastic lesions of the gingiva and to determine the relative prevalence of these lesions in relation to age, sex and site distribution from the biopsy specimens received in the Department of Oral Pathology, MR Ambedkar Dental College and Hospital, Bengaluru and compared such with the reported data in the scientific literature.

\section{MATERIALS AND METHODS}

The material included all consecutive LRHL of the gingiva received for histological diagnosis in the biopsy service of the Department of Oral Pathology, MR Ambedkar Dental College and Hospital, Bengaluru, between 1995 and 2011.

The histological features were studied in $7 \mu \mathrm{m}$-thick paraffin sections stained with hematoxylin and eosin. The lesions included in this study are FFH, PG, POF and PGCG. Most of the lesions could be readily classified into the four main groups, although some were intermediate between PG and FFH. In the latter cases, they were categorized as PG, if the endothelial and inflammatory elements were prominent and FFH if the collagenous component was dominant.

The following criteria were used:

A. Inclusion criteria:

1. All age groups

2. Both male and female sexes

3. Reports with adequate case histories.

B. Exclusion criteria:

1. Subjects taking anticonvulsant drugs, calcium channel blockers and immunosuppressants.

2. Edentulous patient's, i.e. epulis fissuratum.

Data regarding the age and sex of the subjects and the location and type of lesions were obtained from the biopsy register for each case. Histopathologic examination was the method of diagnosis in all cases. Statistical analysis was executed using Microsoft Excel computer software.

\section{RESULTS}

The localized reactive gingival lesions most commonly encountered were focal fibrous hyperplasia representing $38 \%$ of the total lesions $(n=100)$ followed by pyogenic 


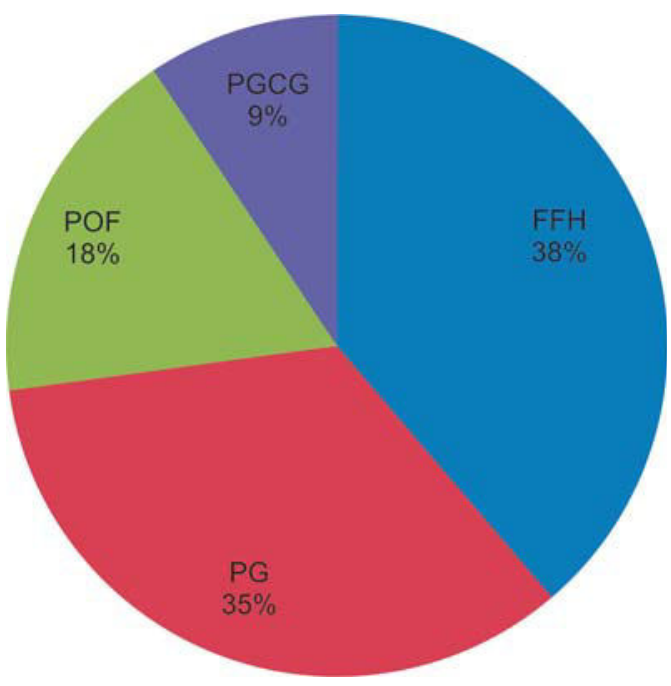

Graph 1: Number of cases of reactive hyperplastic gingival lesions

granuloma which was $35 \%(\mathrm{n}=90)$, peripheral ossifying fibroma which was $18 \%(n=46)$ and $9 \%(n=24)$ peripheral giant cell granuloma (Graph 1).

The gender distribution showed a slight female predilection $(\mathrm{n}=150 ; 58 \%)$ compared to males $(\mathrm{n}=110$; $42 \%$ ) (Table 1).

The mandible $(\mathrm{n}=142 ; 55 \%)$ was more commonly involved than the maxilla $(\mathrm{n}=118 ; 45 \%)$. The majority of localized reactive gingival lesions were detected in the

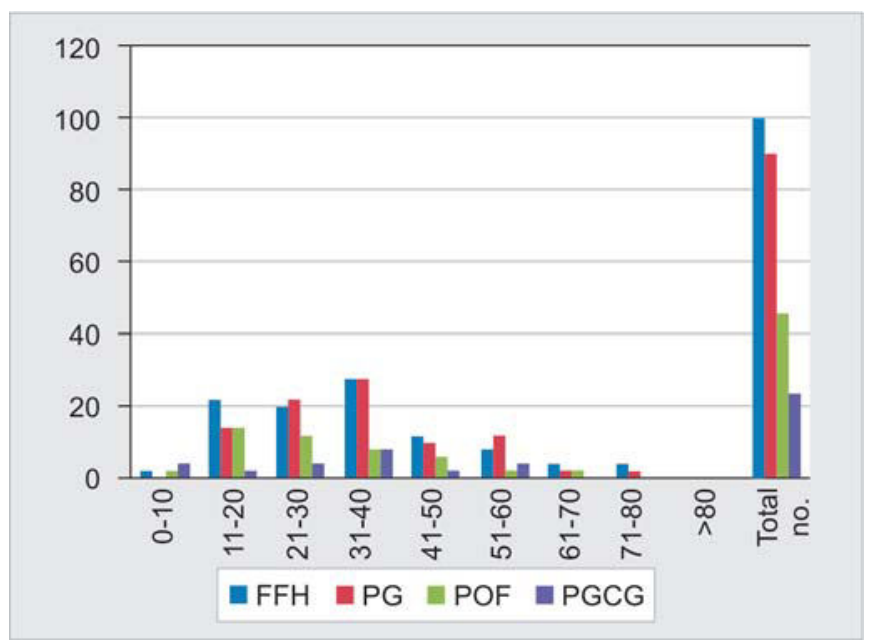

Graph 2: Age distribution of localized reactive hyperplastic lesions mandible followed by the maxilla. In the mandible, focal fibrous hyperplasia and peripheral giant cell granuloma were more common. Pyogenic granuloma and peripheral ossifying fibroma were more common in maxilla (Table 1).

The ages of patients ranged from 9 to 80 years, and most of them were in the age group of 30 to 39 years and it appeared most frequently between the third and fourth decades of life (Graph 2).

\section{DISCUSSION}

Localized reactive hyperplastic lesions of the gingiva are relatively common in biopsy services of oral pathology. The reactive lesions are common in the oral cavity because of the frequency with which the tissues are injured. They can be classified into focal fibrous hyperplasia, peripheral ossifying fibroma, pyogenic granuloma and peripheral giant cell granuloma. ${ }^{4}$ This study is the report on the prevalence of the four main histological types of localized reactive hyperplasia of the gingiva reported in the Oral and maxillofacial pathology, MR Ambedkar Dental College and Hospital, Bengaluru.

Esmeili et al in their review stated that hyperplastic reactive lesions represent as a group the most common oral lesions, excluding caries, periodontal and periapical inflammatory disease. In this group, the second most common group is represented by hyperplastic reactive gingival/alveolar lesions, including inflammatory gingival hyperplasia, oral pyogenic granuloma, peripheral giant cell lesion and peripheral cemento-ossifying fibroma. ${ }^{5}$

According to previous study of Peralles et $\mathrm{al}^{6}$ in their clinicopathologic study conducted on gingival/alveolar hyperplastic reactive lesions observed that inflammatory gingival hyperplasia and oral pyogenic granuloma were the most common diagnosis, which is in agreement with the findings presented here (Table 1).

Focal fibrous hyperplasia is a localized reactive progressive proliferation of oral mucosa in response to injury or local irritation. ${ }^{7}$ Daley et $\mathrm{al}^{8}$ suggested the term 'focal fibrous hyperplasia' which implies a reactive tissue response and is therefore preferable to the term 'fibroma' which implies incorrectly, a benign neoplastic proliferative fibrous connective tissue.

Table 1: Site and sex distribution of reactive hyperplastic gingival lesions

\begin{tabular}{clcccc}
\hline Type of lesions & Total no. of cases & Maxilla & Mandible & Male & Female \\
\hline FFH & $100(38.5 \%)$ & 42 & 58 & 56 & 44 \\
PG & $90(34.6)$ & 48 & 42 & 34 & 56 \\
POF & $46(17.7 \%)$ & 26 & 20 & 46 & 30 \\
PGCG & $24(9.2 \%)$ & 2 & $142(55 \%)$ & $110(42 \%)$ & $150(58 \%)$ \\
\hline Total & 260 & $118(45 \%)$ & & & 20 \\
\hline
\end{tabular}


Focal fibrous hyperplasia of the gingiva manifests clinically as a painless, firm, nodular mass with a smooth surface and normal coloration. ${ }^{9}$

Cooke called all the pedunculated swelling from a mucosal surface as 'polyp' (fibroepithelial polyp), where maximum number of lesions occurred on the mucosa in the line of occlusion, and the entire pedunculated and sessile lesion in the gingiva as 'epulides', which commonly occurred in the maxillary anterior region. ${ }^{10}$ They appear in the interdental papilla as a result of local irritation from calculus; caries or restorations with irregular margins.

Histologically, it consists of a mass of dense collagenous, relatively avascular, connective tissue in a scar-like pattern. Some lesions may contain a mild-to-moderate chronic inflammatory cell infiltrate. ${ }^{7}$ The fibroblast are narrow and elongated and relatively few in number. Recurrences of this lesion are uncommon or rare. ${ }^{9}$ However, Cooke in his review reported three cases of recurrences out of 78 biopsy specimens. ${ }^{10}$

In our study, FFH accounted for $38 \%$ of all cases. Focal fibrous hyperplasia was the most common lesion occurring over a wide age range (9-80 years), with a peak incidence in the third to fourth decades. These observations were in agreement with previous studies. ${ }^{4,8,11}$ The prevalence of male sex was greater than female sex in our study, which is in agreement with authors like Nartey et $\mathrm{al}^{12}$ but differs from the other studies. ${ }^{4,8,11}$ In the current study, FFH was more common in the mandible than in the maxilla, which differs from those reported by Buchner ${ }^{2}$ who reported that maxilla is the most frequently affected.

The term pyogenic granuloma or granuloma pyogenicum was introduced by Hartzell in $1904 .{ }^{13}$ The PG is a relatively common, tumor like, exuberant tissue response to localized irritation or trauma. The name pyogenic granuloma is a misnomer since the condition is not associated with pus and does not represent a granuloma histologically. It is a reactive inflammatory process filled with proliferating vascular channels, immature fibroblastic connective tissue and scattered inflammatory cells. ${ }^{14}$

In our study, pyogenic granulomas were the second most common lesion, comprising $35 \%$ of all LRHL. PG occurred more frequently in the third and fourth decades and showed a female predilection in this study. Similar observations were reported by Kfir et $\mathrm{al}^{3}$ and Angelopoulous ${ }^{15}$ who suggested that the age incidence and female predilection of PG may reflect the influence of pregnancy on the pathogenesis of the disease. Recently, Daley et $\mathrm{a}^{16}$ reported a positive relationship between the incidence of PG and the serum progesterone and estrogen concentrations in pregnant women. It was speculated in this report that the two hormones render the gingival tissue more susceptible to chronic irritation caused by plaque and calculus. About $53.3 \%$ of our cases of PG were found in maxillary gingiva which was lower than those reported by Ababneh (64\%) ${ }^{17}$ and higher than those reported by Zhang et al (47.10\%). ${ }^{18}$

Peripheral ossifying fibroma is a relatively uncommon, solitary, nonneoplastic gingival growth, coined by Eversole and Rovin. ${ }^{11}$ POF is considered a reactive lesion despite the nomenclature that implies a neoplasm. It has been referred to by various names, including 'peripheral fibroma with calcification' and 'calcifying fibroblastic granuloma'. ${ }^{19,20}$

POF resembles clinically and histopathologically to pyogenic granuloma, hence some consider POF to develop secondary to fibrosis of granulation tissue. ${ }^{21}$ POF more commonly occurs in females and in the second decade, hence the role of hormones has also been questioned. ${ }^{22}$ The widely accepted etiopathogenesis for POF is the inflammatory hyperplasia of the cells of the periosteum or periodontal ligament. ${ }^{23,24}$ Chronic irritation of the periosteal and periodontal membrane causes metaplasia of the connective tissue and resulting in initiation of formation of bone or dystrophic calcification. ${ }^{22}$ Multicentric POF can also occur in the oral and maxillofacial region, and have been observed in conditions associated with known genetic mutations, such as, Nevoid basal cell carcinoma syndrome, multiple endocrine neoplasia type II, neurofibromatosis and Gardner syndrome. ${ }^{25}$ The treatment of choice is surgical excision and as POF has a fairly high recurrence rate the mass should be excised deep into the periosteum with complete removal of all irritants. ${ }^{26}$

In our study POF was the third most common lesion, comprising $18 \%$ of all LRHL. POFs in this study occurred mainly in the second and third decades, a finding comparable to that of most other studies. ${ }^{8,11,27}$ The mean age of our patients with POFs was 33.9 years, and this figure was higher than that reported by Kfir et $\mathrm{al}^{3}$ but considerably lower than a study reported by Zhang et al. ${ }^{18}$ The clear female preponderance for POFs in this study was also reported from various studies. ${ }^{2,3,11,28}$ POFs in ours and other studies showed a predilection for the maxilla., ${ }^{2,18,29}$

Peripheral giant cell granuloma is a benign hyperplastic lesion caused by chronic local trauma. PGCG is one of the most frequent giant cell lesions of the jaws and originates from the connective tissue of the periosteum or the periodontal membrane. The peripheral giant cell granuloma, also known as osteoclastoma, peripheral giant cell tumor, reparative giant cell granuloma, giant cell epulis and giant cell hyperplasia of the oral mucosa. ${ }^{30}$

It is manifested clinically by a painless, soft, nodular mass, usually red to reddish-blue in color. It is sometimes ulcerated and bleeds easily when traumatized. The clinical 
appearance resembles PG of the gingiva. Histologically, it consists of a proliferation of mesenchymal cells and multinucleated giant cells with an associated prominent vascularity. Mineralized tissue in the form of woven and/or lamellar bone can be identified in about one-third of these lesions. $^{31}$

In our study PGCG comprising 9\% of all LRHL. In this study, the age of patients ranged from 10 to 55 years with the mean age of 31.6 years and with the highest incidence in the fourth decade of life, similar to other studies mentioned below. Motamedi et $\mathrm{al}^{32}$ reported the average age of 30 years. Katsikeris et al believed the peak incidence to be between 4 th and 5 th decades. ${ }^{33}$ In our study, females were affected more than males which are similar to Giansanti and Waldron studies. ${ }^{34}$ This finding is not in agreement with the findings of Kfir et $\mathrm{al}^{3}$ who showed no sex predilection and Bhaskar et al, ${ }^{35}$ Zhang et al ${ }^{18}$ who reported a slight predilection for the male sex for this lesion. In this study, PGCG occurred more common in the mandible than maxilla; this finding is in agreement with that reported in previous studies. $^{32,34}$

A substantial overlap exists among the different histological entities ${ }^{3,8,11}$ of reactive focal hyperplastic lesions but whether or not they represent the same lesion at different developmental stages as suggested by some workers ${ }^{8,36}$ is debatable. Daley et $\mathrm{al}^{8}$ suggested that the vascular component of $\mathrm{PG}$ is gradually replaced partially or completely by fibrous tissue and hence, diagnosed as organizing pyogenic granuloma or a fibroma. The frequent location of the inflammatory hyperplasia on the gingiva appears to support the notion that they are the same lesion at different stages of histological maturation, but the mean ages for various lesions is not reflecting the progressive development at the different histological stages, in the case of our studies or any of the previous reports. We are of the opinion that FFH, PG, PGCG and POF are mucosal responses to chronic, low grade irritation caused by plaque and calculus, or any other irritant. However, the histological appearance of each entity may be influenced by the intensity of the irritation, duration of the lesion and possibly the metabolic effects of serum concentrations of hormones, such as estrogen and progesterone. Identification of any reactive hyperplastic gingival lesion requires the formulation of differential diagnosis to enable accurate patient evaluation and management.

\section{CONCLUSION}

This study indicates some differences in age and gender distribution as well as in location between the different lesions. Since, this study is a single-centered study, similar studies have to be instituted in other centers of India to draw an inference regarding the epidemiology of gingival lesions. The data presented in this study can be used as a guide for additional multicenter studies. Although LRHL are distinguished on clinical or histopathological grounds, it is important to appreciate that they are variations of the same basic process.

\section{REFERENCES}

1. Rossmann JA. Reactive lesions of the gingiva: Diagnosis and treatment options .The Open Pathology Journal 2011;5:23-32.

2. Buchner A, Calderon S, Ramon Y. Localized hyperplastic lesions of the gingiva: A clinicopathological study of 302 lesions. J Periodontol 1977;48(2):101-04.

3. Kfir Y, Buchner A, Hansen LS. Reactive lesions of the gingiva. A clinicopathological study of 741 cases. J Periodontal 1980;51:655-61.

4. Neville BW, Damm DD, Allen CM, Bouquot JE. Oral and maxillofacial pathology. China: Saunders 2009;507-9;517-23.

5. Esmeili T, Lozada-Nur F, Epstein J. Common benign oral soft tissue masses. Dent Clin North Am 2005;49:223-40.

6. Peralles PG, Viana APB, Azevedo ALR, Pires FR. Gingival and alveolar hyperplastic reactive lesions: Clinicopathological study of 90 cases. Braz J Oral Sciences 2006;5(18):1085-89.

7. Mathur LK, Bhalodi AP, Manohar B, Bhatia A, Rai N, Mathur A. Focal fibrous hyperplasia: A case report. Int J Dent Clin 2010;2(4):56-57.

8. Daley TD, Wysocki G, Wysocki P, Wysocki D. The major epulides: Clinicopathological correlations. J Can Dent Assoc 1990;56(7):627-30.

9. Madhusudan AS, Gupta S, Sowmya GV. Focal fibrous hyperplasia: Report of two cases. International journal of Dental Clinics. 2011:3(1):111-12.

10. Cooke BED. The fibrous epulis and the fibro epithelial polyp: Their histogenesis and natural history. Br Dent J 1952;93: 305-09.

11. Eversole LR, Rovin S. Reactive lesions of the gingiva. J Oral Pathol 1972;1:30-38.

12. Nartey NO. Localized inflammatory hyperplasia of the oral cavity: Clinicopathological study of 165 cases. The Saudi Dental Journal 1994;6(3):145-50.

13. J Hamid, S Majid, M Nooshin. Oral pyogenic granuloma: A review. J of Oral Science 2006;148(4):167-75.

14. Shenoy SS, Dinkar AD. Pyogenic granuloma associated with bone loss in an 8-year-old child: A case report. J Indian Soc Pedod Prev Dent 2006;201-03.

15. Angelopolous AP. Pyogenic granuloma of the oral cavity: Statistical analysis of its clinical features. J Oral Surg 1971;29:840-47.

16. Daley TD, Nartey NO, Wysocki CP. Pregnancy tumor: An analysis. Oral Surg Oral Med Oral Pathol 1991;72:196-99.

17. Ababneh KT. Biopsied gingival lesions in northern Jordanians: A retrospective analysis over 10 years. Int J Periodontics Restorative Dent Aug 2006;26(4):387-93.

18. Zhang W, Chen Y, An Z, Geng N, Bao D. Reactive gingival lesions: A retrospective study of 2,439 cases. Quint Int Feb 2007;38(2):103-10.

19. Zain RB, Fei YJ. Fibrous lesions of the gingiva: A histopathological analysis of 204 cases. Oral Surg Oral Med Oral Pathol 1990;70:466-70. 
20. Waldron CA. Fibro-osseous lesions of the jaws. J Oral Maxillofac Surg 1993;51:828-35.

21. Shivaprasad, Shridhara B Reddy, Sudhir R Patil, Nagaraj B Kulburgi, RS Puranik. Peripheral ossifying fibroma and pyogenic granuloma. Are they interrelated? New York State Dental Journal 2008;74(2):50-52.

22. Miller CS, Henry RG, Damm DD. Proliferative mass found in the gingival. J Am Dent Assoc 1990;121:559-60.

23. Neville BW, Damm DD, Allen CM, Bouquot JE. Soft tissue tumors. Oral and maxillofacial pathology (3rd ed). Missouri; Elsevier 521-3.12.

24. Delbem ACB, Cunha RF, Silva JZ, Soubhia AMP. Peripheral cemento-ossifying fibroma in child. A follow-up of 4 years. Report of a case. Eur J Dent 2008;2:134-37.

25. Kumar SKS, Ram S, Jorgensen MG, Shuler CF, Sedghizadeh PP. Multicentric peripheral ossifying fibroma. J Oral Sci 2006;48:239-43.

26. Kendrick F, Waggoner WF. Managing a peripheral ossifying fibroma. J Dent Child 1996;63:135-38.

27. Stablein MJ, Silverglade LB. Comparative analysis of biopsy specimens from gingiva and alveolar mucosa. J Periodontol 1985;56:671-76.

28. Shamim T, Varghese VI, Shameena PM, Sudhas S. A retrospective analysis of gingival biopsied lesions in South India population 2001-2006. Med Oral Pathol Oral Cir Bucal 2008;13:E441-48.

29. Cuisia ZE, Brannon RB. Peripheral ossifying fibroma: A clinical evaluation of 134 pediatric cases. Pediatr Dent 2001;23(3): 245-48.

30. Chaparro-Avendano AV, Berini-Aytes L, Gay-Escoda C. Peripheral giant cell granuloma. A report of five cases and review of the literature. Med Oral Patol Oral Cir Bucal 2005;10(1):53-57.
31. Dayan D, Buchner A, Spirer S. Bone formation in peripheral giant cell granuloma. J Periodontol 1990;61(7):444-46.

32. Motamedi MH, Eshghyar N, Jafari SM, Lassemi E, Navi F, Abbas FM, et al. Peripheral and central giant cell granulomas of the jaws: A demographic study. Oral Surg Oral Med Oral Pathol Oral Radiol Endod 2007;103(6):e39-43.

33. Katsikeris N, Kakarantza-Angelopoulou E, Angelopoulos AP. Peripheral giant cell granuloma. Clinicopathologic study of 224 new cases and review of 956 reported cases. Int J Oral Maxillofac Surg 1988;17(2):94-99.

34. Giansanti JS, Waldron CA. Peripheral giant cell granuloma: A review of 720 cases. J Oral Surg 1969;27(10):787-91.

35. Bhaskar SN, Cutright DE, Beasley JD, Perez B. Giant cell reparative granuloma (peripheral): Report of 50 cases. J Oral Surg 1971;29(2):110-15.

36. Shafer WG, Hine MK, Levy BM. Shafer's textbook of oral pathology (6th ed). Philadelphia: Elsevier 2009;328.

\section{ABOUT THE AUTHORS}

\section{Sangeetha Ramu (Corresponding Author)}

Senior Lecturer, Department of Oral and Maxillofacial Pathology KLE's Dental College and Hospital, Bengaluru, Karnataka, India e-mail: sangeethasrikanth04@gmail.com

\section{Charlotte Rodrigues}

Professor and Head, Department of Oral and Maxillofacial Pathology MR AmbedkarDental College and Hospital, Bengaluru, Karnataka, India 